\title{
Prediction of hospitalization and blood transfusion requirement in patients with macroscopic hematuria
}

\author{
๑D Hasan Basri Çetinkaya, @Harun Güneş \\ Balıkesir University, School of Medicine, Department of Emergency Medicine, Balıkesir, Turkey
}

Cite this article as: Çetinkaya HB, Güneş H. Prediction of hospitalization and blood transfusion requirement in patients with macroscopic hematuria. Anatolian Curr Med J 2021; 3(4); 315-318.

\begin{abstract}
Aim: It was aimed to find out simple parameters that can be used in the emergency triage and can discriminate patients requiring hospitalization or blood transfusion (BT) among those presenting with macroscopic hematuria (MH).

Material and Method: Medical records of the patients presenting to the emergency department (ED) with MH were investigated retrospectively. The patients' vital signs including pulse rate (PR), systolic blood pressure (SBP) and diastolic blood pressure, and laboratory test results including hemoglobin, platelet count and international normalized ratio were recorded. Shock index (SI) was calculated using SBP and PR of each patient.

Results: Seventy seven patients were recruited into the study. PR and SI were found to significantly differ between the patients discharged from the ED and those who needed hospitalization. Hospitalized patients were seen to have higher PR values and SI compared to discharged ones. PR and SI were higher in patients requiring BT compared to those who did not require transfusion.

Conclusion: Use of PR and SI in the emergency triage may be helpful while discriminating patients who need hospitalization or BT among those presenting with $\mathrm{MH}$.
\end{abstract}

Keywords: Macroscopic hematuria, hospitalization, blood transfusion, shock index, pulse rate

\section{INTRODUCTION}

Macroscopic hematuria $(\mathrm{MH})$ is one of the leading symptoms which cause considerable anxiety although it is not one of the commonest symptoms encountered in the emergency department (ED). The most significant final diagnosis is urologic cancer which may occur in renal, ureteric, bladder or prostatic level. The other possible diagnoses include benign prostatic hyperplasia, urolithiasis, urinary tract infection and renal problems. Less commonly urinary tract injury may also lead to $\mathrm{MH}$ (1-5). MH patients generally admit to the hospital through the ED. Recognition of those patients and determining a suitable diagnostic and therapeutic management strategy are significant (6). Most of the $\mathrm{MH}$ patients can be discharged from the ED and seen again for more detailed evaluation at the outpatient clinic within 2 weeks (6-8). On the other hand, some of the patients may need admission for hospitalized follow-up or rarely for surgical intervention. There are no guidelines for management of $\mathrm{MH}$ patients in ED so those patients are often inappropriately discharged or referred to another medical facility (9).
We suggest that a simple and catchy method to recognize $\mathrm{MH}$ patients would help physicians. Blood pressure and pulse rate (PR) are routinely measured in EDs to determine the severity of the patient's clinical condition. Shock index (SI) can be calculated easily in the early period during the ED triage. Literature includes previous studies reporting that SI can be used to predict prognosis in patients with hypovolemia, sepsis, myocardial infarction and pneumonia (10-12). SI is a simple parameter calculated with the formula PR divided by systolic blood pressure (SBP), and it provides more reliable information about the hemodynamic status than PR or SBP does individually (13). Normal range of SI is 0.5 to 0.7 (14).

The current study aimed to find out simple parameters which help the physician determine the patients with more critical condition in the early period by helping discriminate those requiring hospitalization or blood transfusion (BT) among all admissions related to $\mathrm{MH}$. 


\section{MATERIAL AND METHOD}

The study was approved by the Balıkesir University Faculty of Medicine Clinical Researchs Ethics Committee (Date: 19.08.2020, Decision No: 2020/140). All procedures were carried out in accordance with the ethical rules and the principles of the Declaration of Helsinki.

The present study was performed by retrospectively investigating the hospital records of $\mathrm{MH}$ patients above 18 years of age who admitted to ED of a university hospital. Patients below 18 years of age and those who refused the treatment and left the ED before his or her observation period completed were excluded from the study. A patient was recruited into the study if he or she was diagnosed with $\mathrm{MH}$ by the emergency physician and the diagnosis was confirmed by the consulting urologist. Gender, age, comorbidities, blood-thinning medication (anticoagulant or antiplatelet) use and vital signs (PR, SBP and diastolic blood pressure (DBP)) of the patients were taken from their charts stored in the hospital's archive. Results of laboratory tests including hemoglobin (Hmg), platelet count (Plt) and international normalized ratio (INR) were recorded. The patients were grouped in terms of $\mathrm{BT}$ requirement in the $\mathrm{ED}$ and their outcome (hospitalized or discharged from the ED).

\section{Statistical Analysis}

Shapiro-Wilk test was used to test the normality of variables. Continuous variables were presented as mean \pm standard deviation for normally distributed variables and with median $\left(25^{\text {th }}\right.$ percentile- $75^{\text {th }}$ percentile) values for non-normal variables. Categorical variables were expressed by number and percentages. Receiver operating characteristics (ROC) curve analysis was performed to evaluate and compare the performances of diagnostic markers. Youden J index was used to obtain optimal cut-off value, and related sensitivity, specificity, positive predictive and negative predictive values were given. Significance level was taken as $\alpha=0.05$. Statistical analyses were performed with IBM SPSS Statistics version 22.0 (IBM Corp., USA) and MedCalc version 12.3.0.0.

\section{RESULTS}

The study included 77 patients, with a median age of 73 (66-83). Among 77 patients, 67 (87\%) were male. The demographic and laboratory data of the patients were given in Table 1.

Of the 77 patients, 27 (35.06\%) were discharged from the hospital and $50(64.94 \%)$ patients were hospitalized. While $26(33.77 \%)$ of the patients required BT, 51 (66.23\%) did not require. We performed ROC curve analyses to evaluate the diagnostic performances of SI, PR, SBP and DBP in discriminating discharged patients from those who were hospitalized. Considerably good diagnostic performances were obtained for SI (AUC=0.647, $\mathrm{p}=0.028)$ and PR (AUC=0.689, $\mathrm{p}=0.004)$. But these two parameters were seen to not differ significantly in terms of their diagnostic performances while predicting the patients who needed hospitalization $(\mathrm{p}=0.380)$. Also ROC curve analyses were performed to evaluate the diagnostic performances of these variables in discriminating patients who required $\mathrm{BT}$ from those who didn't require. SI (AUC=0.646, $\mathrm{p}=0.039)$ and PR (AUC $=0.662, p=0.016$ ) also had relatively good performances in discriminating patients who needed BT from those who didn't. They were also seen to not differ significantly in terms of their diagnostic performances while predicting the patients who needed BT $(\mathrm{p}=0.728)$. Optimal cut-off values were obtained according to Youden J index; corresponding sensitivity and specificity values are given (Table 2, Figure 1, 2).

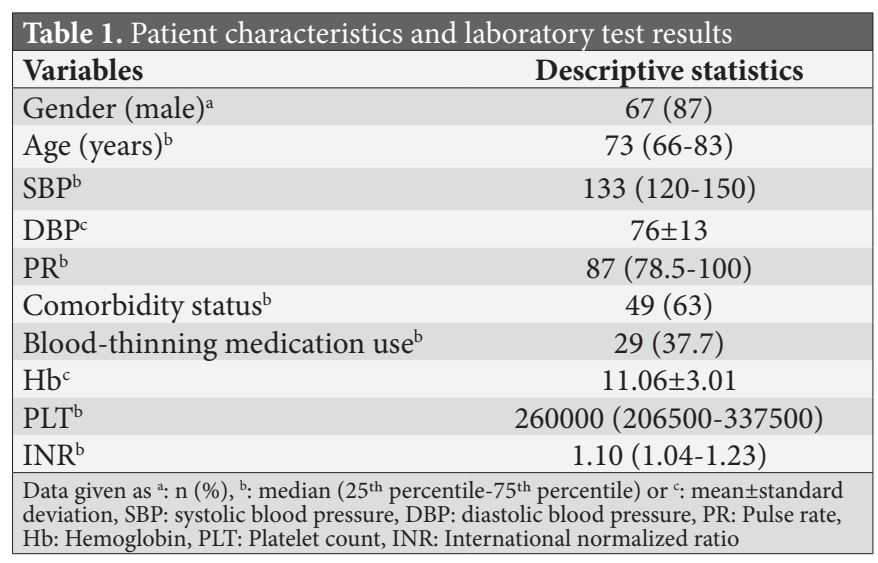

Table 2. ROC curve analyses for SI, PR, SBP and DBP in discriminating patients who were discharged and hospitalized, and who required

\begin{tabular}{|c|c|c|c|c|c|c|c|c|}
\hline & & AUC & $\begin{array}{c}\mathbf{p} \\
\text { value }\end{array}$ & $\begin{array}{l}\text { cut-off } \\
\text { value }\end{array}$ & $\begin{array}{c}\text { Sensitivity } \\
(95 \% \text { CI })\end{array}$ & $\begin{array}{l}\text { Specificity } \\
(95 \% \text { CI })\end{array}$ & $\begin{array}{c}\text { PPV } \\
(95 \% \text { CI })\end{array}$ & $\begin{array}{c}\text { NPV } \\
(95 \% \text { CI })\end{array}$ \\
\hline \multirow{4}{*}{$\begin{array}{l}\text { Hospitalization } \\
\text { requirement }\end{array}$} & SBP & 0.505 & 0.944 & $\leq 117$ & $28.00(16.20-42.50)$ & $88.89(70.80-97.60)$ & $82.40(59.50-93.70)$ & $40.00(34.90-45.30)$ \\
\hline & DBP & 0.567 & 0.333 & $\leq 70$ & $48.00(33.70-62.60)$ & $66.67(46.00-83.50)$ & $72.70(59.30-83.00)$ & $40.90(32.20-50.20)$ \\
\hline & Pulse rate & 0.689 & 0.004 & $>80$ & $76.00(61.80-86.90)$ & $55.56(35.30-74.50)$ & $76.00(66.90-83.20)$ & $55.60(40.70-69.40)$ \\
\hline & SI & 0.647 & 0.028 & $>0.68$ & $62.00(47.20-75.30)$ & 74.07 (53.70-88.90) & $81.60(69.30-89.70)$ & $51.30(40.90-61.50)$ \\
\hline \multirow{4}{*}{$\begin{array}{l}\text { Blood } \\
\text { transfusion } \\
\text { requirement }\end{array}$} & SBP & 0.567 & 0.325 & $\leq 132$ & $61.54(40.60-79.80)$ & $56.86(42.20-70.70)$ & $42.10(31.90-53.00)$ & $74.40(62.80-83.30)$ \\
\hline & DBP & 0.620 & 0.078 & $\leq 66$ & $38.46(20.20-59.40)$ & $82.35(69.10-91.60)$ & $52.60(34.00-70.50)$ & $72.40(65.40-78.50)$ \\
\hline & Pulse rate & 0.662 & 0.016 & $>91$ & $61.54(40.60-79.80)$ & $72.55(58.30-84.10)$ & $53.30(40.00-66.20)$ & $78.70(68.90-86.10)$ \\
\hline & SI & 0.646 & 0.039 & $>0.8$ & $42.31(23.40-63.10)$ & $90.20(78.60-96.70)$ & $68.70(46.10-85.00)$ & $75.40(68.60-81.20)$ \\
\hline
\end{tabular}

AUC: Area under the curve, CI: Confidence interval, SBP: systolic blood pressure, DBP: diastolic blood pressure, SI: shock index 


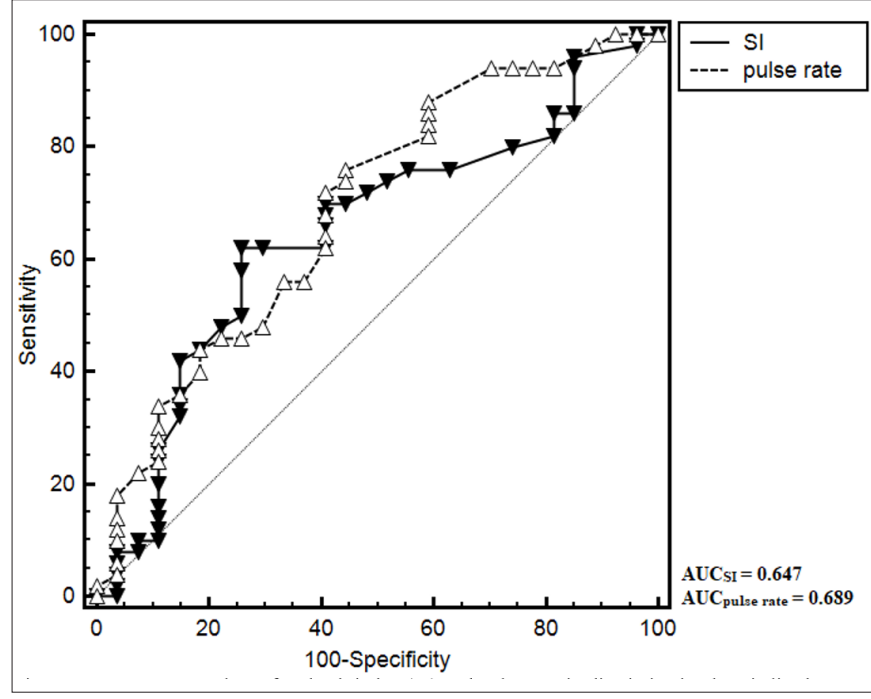

Figure 1. ROC curve analyses for shock index (SI) and pulse rate in discriminating hospitalized patients from those who were discharged

\section{DISCUSSION}

Urinary bladder-originated persistent hematuria refractory to therapeutic interventions may be lifethreatening, and is still a hard-to-treat problem. When bladder irrigation with triple lumen urinary catheter and fulguration of bleeding lesions fails to stop bleeding, and the rate of BT cannot catch up that of bleeding, a life-threatening condition may ensue. Any patient with signs of cardiovascular compromise related to blood lose should be resuscitated with volume replacement, correction of coagulopathy and therapies directed to restore hemostasis in the ED (15). Patients without any cardiovascular compromise may be managed on an out-patient setting if they do not have any other feature necessitating in-patient follow-up such as sepsis, acute renal failure, thrombus retention, inability to take sufficient fluids orally, serious comorbidities and social concerns (9).

To the best of the authors' knowledge, there are no studies in the English literature evaluating the predictive power of possible simple parameters while determining hospitalization or BT requirement in patients presenting to $\mathrm{ED}$ due to $\mathrm{MH}$. The current study seems to be the first one evaluating this topic. All of the patients recruited into the current study were consulted with the Urology Department and admitted to hospital in the case of need for in-patient follow-up. It was seen in a study by Goonewardena et al. (16) that 130 of 156 macroscopic hematuria patients were male and only 26 patients were female; the current study also showed that a significantly higher number of the patients presenting to the ED with MH were male. A study by Rockall et al. (17) showed that incidence of hematuria increases after the age of 40 which is also a threshold for significantly increased risk of urologic malignancy of which prostatic cancer is the

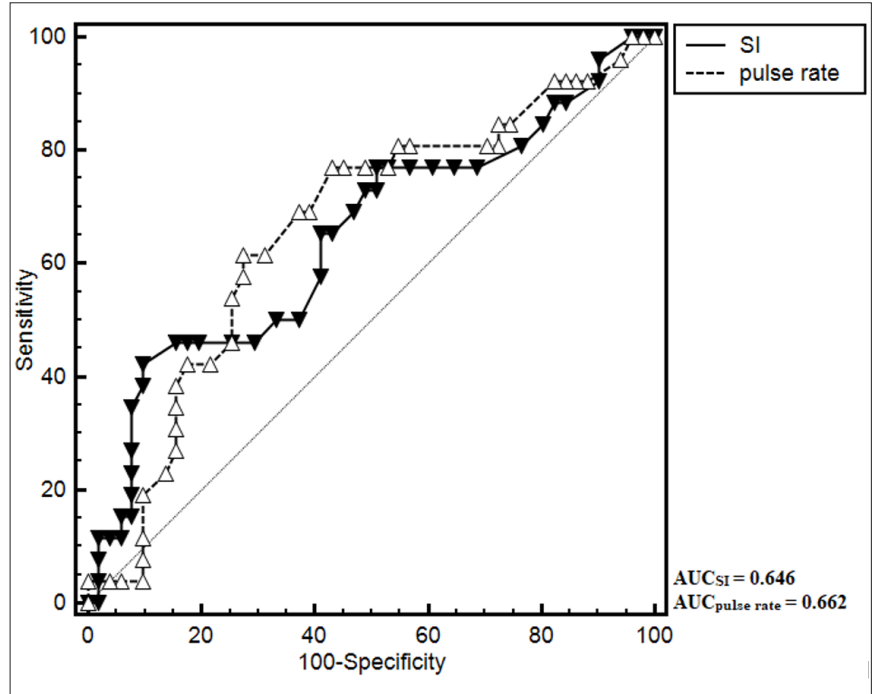

Figure 2. ROC curve analyses for shock index (SI) and pulse rate in discriminating patients who required BT and those who didn't

most important one. And, the mean age of the patients was found 73 years in the present study. We suggest that higher number of the patients having comorbidities in the current study may be related to higher number of older ones among all recruited patients. Rate of bloodthinning medication use was found to be low in the present study. Culclasure et al. (18) suggested that information regarding anti-coagulant medication use related to cardiac or cerebral vascular disease must be gathered but their results indicated that anti-coagulants do not cause hematuria because incidence of hematuria was found to be lower in the group using anti-coagulant medication compared to the control group.

The results of the largest retrospective study evaluating predictive power of SI in determining hospitalization requirement among all $\mathrm{ED}$ admissions indicated that SI may be a fast and accurate marker while predicting need for hospital admission (19). SI was also shown to predict the need for intensive care unit admission in patients with gastrointestinal bleeding (20). In the present study, most of the patients with $\mathrm{MH}$ were admitted to the hospital, and SI (AUC=0.647, $\mathrm{p}=0.028$ ) and PR (AUC $=0.686$, $\mathrm{p}=0.004)$ were seen to have significantly good diagnostic performances. While predicting need for hospitalization, cut-off values for SI and PR were calculated as $>0.68$ and $>80$ beats/min, respectively. Saffouri et al. (21) found that SI is useful when predicting need for major transfusion, which means more than 4 units of erythrocyte suspension, in patients with upper gastrointestinal hemorrhage. ElMenyar et al. (22) reported that SI can be used to predict massive BT or laparotomy requirement and mortality in trauma patients. The optimal cut-off value of SI when predicting need for massive BT was 0.81 . TercerosAlmanza et al. (23) stated that SI is a good predictor of massive hemorrhage in trauma patients and, it can be added to the initial diagnostic work-up of patients with 
severe trauma. It was seen in the current study that some of the patients with $\mathrm{MH}$ needed BT, and SI (AUC=0.646, $\mathrm{p}=0.039)$ and $\mathrm{PR}(\mathrm{AUC}=0.662, \mathrm{p}=0.016)$ had significant predictive powers when determining those with the need for BT. Cut-off values for PR and SI related to BT requirement were $>91$ beats/min and $>0.8$, respectively.

The present study has mainly two significant limitations; the first one is relatively small number of the patients recruited into the study and the second one is design of the study as a single-center one.

\section{CONCLUSION}

Although some of the patients with $\mathrm{MH}$ can be managed on an out-patient setting, the others need inhospital follow-up and BT, and the results of this study suggests that use of PR and SI in the emergency triage may be helpful while discriminating patients who need hospitalization or BT. However, none of them had perfect diagnostic test criteria results so the physicians should not solely rely on these parameters

\section{ETHICAL DECLARATIONS}

Ethics Committee Approval: The study was approved by the Balikesir University Faculty of Medicine Clinical Research Ethics Committee (Date: 19.08.2020, Decision No: 2020/140).

Informed Consent: Because the study was designed retrospectively, no written informed consent form was obtained from patients.

Referee Evaluation Process: Externally peer-reviewed.

Conflict of Interest Statement: The authors have no conflicts of interest to declare.

Financial Disclosure: The authors declared that this study has received no financial support.

Author Contributions: All of the authors declare that they have all participated in the design, execution, and analysis of the paper, and that they have approved the final version.

Ackowledgements: The authors would like to thank Associate Professor Deniz Siğırlı of Bursa Uludag University School of Medicine Biostatistics Department for her invaluable help in doing statistical analyses.

\section{REFERENCES}

1. Amling CL. Diagnosis and management of superficial bladder cancer. Curr Probl Cancer 2001; 25: 219-78.

2. Smet CE, De Hurtado JM, Pareja RR, et al. Analysis of 895 consultations for hematuria in the emergency department in an urology unit. J Urol (Paris) 1996; 102: 168-71.

3. Mommsen S, Aagaard J, Sell A. Presenting symptoms, treatment delay and survival in bladder cancer. Scand J UrolNephrol 1983; 17: 163-7.
4. Goonewardena SA, AbeygunasekeraAM. Haematuria as the presenting symptom: experience from a tertiary referral centre in Sri Lanka. Ceylon Med J 1998; 43: 156-8.

5. Rodgers $M$, Nixon J, Hempel S, et al. Diagnostic tests and algorithms used in the investigation of haematuria: systematic reviews and economic evaluation. Health Technol Assess 2006; 18: 259 .

6. Paul AB, Collie DA, Wild SR, Chisholm GD. An integrated haematuria clinic. Br J ClinPract 1993; 47: 128-30.

7. Wallace DM, Bryan RT, Dunn JA, et al. Delay and survival in bladder cancer. BJU Int 2002; 89: 868-78.

8. Thiruchelvam N, Mostafid H. Do patients with frank haematuria referred under the two-week rule have a higher incidence of bladder cancer? Ann R CollSurg Engl 2005; 87: 345-7.

9. Hicks D, Li CY. Management of macroscopic haematuria in the emergency department. Emerg Med J 2007; 24: 385-90.

10. Sankaran P, Kamath AV, Tariq SM, et al. Are shock index and adjusted shock index useful in predicting mortality and length of stay in community-acquired pneumonia? Eur J Intern Med 2011; 22: $282-5$

11. Semerci E, Durukan P, Yıldırım S, Baykan N, Yakar Ş, İpekten F. The effect of shock index and hematocrit levels on mortality in patients with gastrointestinal bleeding. Turk J Acad Gastroenterol 2018; 17: 85-9.

12. Mutschler M, Nienaber U, Münzberg M, et al. The shock index revisited - a fast guide to transfusion requirement? A retrospective analysis on 21,853 patients derived from the Trauma Register DGU ${ }^{\circledR}$. Crit Care 2013; 17: R172.

13. Rassameehiran S, Teerakanok J, Suchartlikitwong S, Nugent K. Utility of the shock index for risk stratification in patients with acute upper gastrointestinal bleeding. South Med J 2017; 110: 738-43.

14. Otero R, Nguyen B. Şoktaki hastaya yaklaşım. In: Yıldıray Ç., editor. Acil Tip KapsamlıBirÇalışmaKlavuzu. 7th edition. İstanbul: Nobel Tip Kitabevi; 2013. p. 165-172

15. Choong SK, Walkden M, Kirby R. The management of intractable haematuria.BJU Int 2000; 86: 951-9.

16. Goonewardena SA, Abeygunasekera AM. Haematuria as the presenting symptom: experience from a tertiary referral centre in Sri Lanka. Ceylon Med J 1998; 43: 156-8.

17. Rockall AG, Newman-Sanders AP, al-Kutoubi MA, et al. Haematuria. Postgrad Med J 1997; 73: 129-36

18. Culclasure TF, Bray VJ, Hasbargen JA. The significance of hematuria in the anticoagulated patient. Arch Intern Med 1994; 154: 649-52.

19. Al Jalbout N, Balhara KS, Hamade B, Hsieh YH, Kelen GD, Bayram JD. Shock index as a predictor of hospital admission and inpatient mortality in a US national database of emergency departments. Emerg Med J 2019; 36: 293-7.

20. Kocaoğlu S, Çetinkaya HB. Use of age shock index in determining severity of illness in patients presenting to the emergency department with gastrointestinal bleeding. Am J Emerg Med 2021; 47: 274-8.

21. Saffouri E, Blackwell C, Laursen SB, et al. The shock index is not accurate at predicting outcomes in patients with upper gastrointestinal bleeding. Aliment PharmacolTher 2020; 51: 253-60.

22. El-Menyar A, Goyal P, Tilley E, Latifi R. The clinical utility of shock index to predict the need for blood transfusion and outcomes in trauma. J Surg Res 2018; 227: 52-9.

23. Terceros-Almanza LJ, García-Fuentes C, Bermejo-Aznárez S, et al. Prediction of massive bleeding. shock index and modified shock index. Med Intensiva 2017; 41: 532-8. 